\title{
The Winneba Fancy Dress Festival: Colours of Emblems and Costumes, and Their Influence on Masqueraders Performances
}

\author{
Stephen Osei Akyiaw \\ Department of Graphic Design, University of Education, Winneba. P. O. Box 25, Winneba. Ghana \\ *soakyiaw@uew.edu.gh
}

\begin{abstract}
Despite the special prominence of colours in any visual design and acts, costumes and acts and their relative importance displayed in the Winneba Fancy Dress (Masquerade) festival have not been investigated. The study adopted a qualitative research approach to understand the importance of colours of costumes and acts and their roles in the Winneba Fancy Dress (Masquerade) festival. Five groups were purposively selected for the study. Observation and interviews were employed as data collection methods. The data were analysed thematically. The study disclosed that colours used to display some cultures familiar among the Europeans, Americans, and Asians were displayed in the Masquerade Festival. Additionally, it was revealed that the colours used to make the costumes for the Masqueraders, to some extent, got them to act in ways based on the nature and colours of the costume. The study also found that the colours depicted unity, culture, and acting elements in the masquerade festival. In line with these findings, the study recommends that graphic designers experiment with more colours and costume displays during the Masquerade Festival to develop other eccentric harmonious colour costumes and acts applied in other traditions.
\end{abstract}

Keywords: Acts, colours, costumes, festival, masquerade.

DOI: $10.7176 / \mathrm{ADS} / 99-03$

Publication date: February $28^{\text {th }} 2022$

\section{Introduction}

Colour plays a unique role in the discharge of humanity's daily activities. Identification of things around us makes movements simple. Colour has been that element that helps in identifying things quickly. Colours can influence thinking, alter actions, and generate reactions based on how it is perceived, represented, and played. It is a powerful communication medium that is irreplaceable (Eru, 2013). Colour adds excellent meaning to communication as it vitalises the visual variety of messages and delivers an instant impression that is often universally understood from a distance (Eru, 2013; Schloss, Lessard, Walmsley \& Foley, 2018). As a result, it could be said that, without the existence of colour, identifying things easily and quickly would have been chaotic. Colour identification is perception. It is only perceived with a reflection of light from an angle. A particular colour can be perceived differently due to several factors, including the individual and the environment. The vocabulary of colour is described as the visual reaction to the wavelength of sunlight interpreted as red, blue, green, and others. Every image is represented by its physical properties of hue, intensity, and value and portrays an individual's psychological and emotional stance.

Morse and Volley (2018) note that psychology of color looks at two main views: the relationship between color and emotions. One school of thought holds that this relationship is culturally determined and varies across people and cultures. The other suggests a more psychophysiological basis for this relationship between colour and mood, which implies that it is universal. However, in marketing, colour psychology looks at how colour influences the behaviour and decision-making of consumers. Different colours can impact the way consumers perceive a brand. It is said that humans are visual creatures, so what humans perceive visually plays a much more significant role in influencing what we decide to buy or do than we might think.

As an individual or group perceives, colour symbolizes many things and has several meanings. It can symbolise a rite of passage, differentiate a premium from a discount brand, and distinguish between fun and seriousness, young and old, male and female (De Bortoli \& Maroto, 2001). Eru (2013) also posits that colour has a solid attachment to religious, cultural, political, and social influences. It is one of many visual features that can be used to communicate abstract information with others, including size, texture, orientation, and shape (Bertin, 1983; Ware, 2012). However, color is beneficial for signaling because it can be observed quickly from a distance and provides meaningful information independent of spatial structure (Schloss et al., 2018). The use of different colours evokes different sensations and also helps in understanding. Different colours can affect moods and emotions dramatically (Cox, 2021). In festivals, people wear certain colours to align with some groups' specific colours and preferences. The inferences above can also connote that humans can behave in a particular way based on the kind of colour they see.

Several studies have been done concerning colour and its uses in society. A study by Pierson (2008) looked at how colour influences visual communication. The study showed that the usage of colour adds tremendous meaning to communicating visually. Schloss et al. (2018) also studied colour inferences in visual communication, 
that is, the meaning of colour in recycling. It came to light that one colour can be associated with many different concepts, and many colours can be associated with the same concept, which is one concept. Elliot et al. (2007) studied colour and its psychological functioning. It looked at the effect of red on performance attainment. DeGraft-Yankson (2020) examined the concept of colour amongst the Akan people of Ghana. The study pointed to how colour falls significantly within the traditional lives of the Akan people, which has cultural and spiritual signification. Agyarkoh, Duku and Abban (2017) also examined colour symbolism in Aboakyir, which is a deer festival famous and celebrated among the people of Effutu in Winneba, which is in the Central Region of Ghana. The purpose of the preceding study looked into the colours used to celebrate the Simpa Aboakyir festival during the 2016 edition. In another perspective, Emiemokumo (2012) studied Visual Art form in motion: traditional African masquerade as a theatrical phenomenon. A masquerade is seen as a visual and performing art in the study. The masquerade performances also satisfy a need for aesthetic expression, provide a recreational outlet, and promote unity among various factions.

Although there have been studies on festivals as indicated above, there seem not to be studies that have focused on how colours are used in the entire process of the Winneba Masquerade Festival, which is popularly known as Fancy Dress Festival, and how the masqueraders use colours in their performances during the festival. In the light of the above, this study examined how masqueraders used colours and how colours used for the costumes influenced the actions of masqueraders during the Winneba Fancy Dress Festival.

The following research questions were formulated for the study:

1. How do masqueraders use colours to act during the Fancy Dress Festival?

2. In what way do colours used for the costumes influence the actions of masqueraders during the Fancy Dress Festival?

\section{Brief History of Fancy Dress in Winneba}

Winneba Travel Guide records that the Winneba Masquerade Festival can be traced from colonial Ghana when the Dutch and English settlers wore masks at New Year parties. The Masquerade Festival has become a second festival for the people of Winneba. The festival is locally termed Kaakamotobi, which means to scare. It was modernized and termed Masquerade Festival. The name "Masquerade" was used by the Egyaa group, a group of fishermen who could not speak English and had difficulty saying "masquerade." Instead, they preferred the term "Fanti dress" (Brown, 2005). The people of Winneba began forming masquerade groups in the 1920s to poke fun at the life and dress of the Europeans. After independence in Ghana in 1957, President Kwame Nkrumah approved the annual festival.

The Winneba Masquerade Federation started the Winneba Fancy Dress Festival. The "Fanti dress" festival is held every $1^{\text {st }}$ January by the people of Winneba in the Central region of Ghana (Modernghana, 2020). According to the Winneba Travel Guide, the Masquerade Festival in Winneba started with four powerful groups coming together to celebrate the festival and compete for the first position. These four groups are Nobles No. 1; Egyaa No. 2; Tumus No. 3 and Red Cross No. 4. Within half a decade, a fifth group emerged named the Royals No. 5. The groups are made up of women, men, boys, and girls, and they work to impress the judges with different dance routines throughout the day.

The festival is inspired by colour, music, and dance. The festival is the definition of colour, style, and awe. The masqueraders compete for honours in march past, highlife, and speed dance. They dress in colourful costumes and wear fancy and fierce masks.

\section{Methodology}

This paper is a qualitative study that aims at understanding the significance of colours of costumes and acts in the Winneba Masquerade Festival. The study further hinges on a case study that examines the phenomenon within its real-life context. The context of the events being studied is critical, and the researcher has no control over the events as they unfold (Yin, 2014). Data were collected via interviews and observations. A face-to-face interview was used in this study. Interviews were conducted to bring forth views and opinions from the participants to gain insight and understanding of the participant's perspectives and experiences that could not be observed effectively by other means. The interviews were conducted from the emic and etic perspectives, and each interview session lasted for 10 to 20 minutes.

The Winneba Masquerade Festival was sampled because it is Ghana's first and most publicised and famous masquerade festival. To retain the depth and richness of data, the researcher purposively sampled 5 participants who understood the phenomenon under study and were willing to provide information by their experience with the festival (Bernard, 2002). The study period was two Masquerade Festivals, namely, 2019 and 2020. The researcher keenly observed all the activities and performances that were displayed. The researcher carried a field note pad to take notes and recorded observed behaviours and actions of the participants as they unfolded. The interviews were conducted in Twi, Fanti, and English language. The ones conducted in Twi and Fanti dialects were transcribed and translated by an Academic translator. 
The data collected were carefully assembled and prepared. Patterns and themes were drawn from the data collected (Braun \& Clarke, 2006). The patterns and themes were drawn to have a clear view, description, and understanding of the issues in greater detail (Flick, 2013). After having a full grasp of the issues in the data, specific dominant themes emerged following the inductive form of thematic analysis.

\section{Discussion of findings}

\section{Representation, Colour Identification, Meaning, and Significance}

The study revealed several aspects of the festival concerning the use of colours. The Winneba Fancy Dress festival is usually represented by the people of Winneba, some of whom form part of any of the groups that participate in the festival. The festival is led and organized by Winneba Masquerade Federation.

The Winneba Masquerade Federation organises the festival. The federation has a multicoloured logo (Fig. 1 below), which signifies diverse people. This research revealed that Red Cross was the only group with its unique color: their traditional red. The rest of the groups initially did not have corporate colours until the federation advised the other groups to choose their preferred colours some few years ago.

All the groups under the federation currently have their corporate colours, which are well represented on their emblems. Participants of the groups use flags of their emblems to show their presence. Some of the participants of the groups exhibited certain characters based on how some colours of fabrics were used to design costumes and their accompanying artifacts.

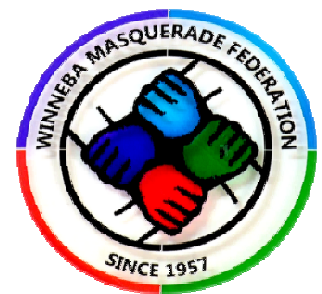

Figure. 1.The Logo of the Winneba Masquerade Federation (Source: Fieldwork, 2019)

Figure 1. above depicts the exhibition of four colours representing the four initial groups of the federation. The logo is made up of shade and tint of blue, green, and red. The four colours were used for the hands and the outer circles. This exact figure communicates the bond and unity among all the federation groups. Unity is seen in how all the four hands have been clenched, holding the wrist of each other.

Below are the emblems of all the groups that form the federation.

Nobles No. 1

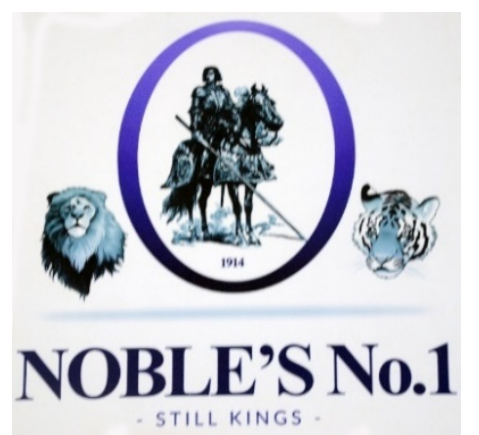

Figure 2. Emblem of Noble's No. 1 (Source: Fieldwork, 2019)

The colours of nobles are mauve (purple) and white. According to Cerrato (2012), purple is associated with royalty. It symbolizes power, nobility, luxury, and ambition. It also conveys wealth and extravagance. Cerrato's meaning of the purple being royalty and power is justified by the power willed by the nobleman sitting on the horse.

The Noble's symbol bears a man sitting on a horse holding a spear, with the heads of a lion and tiger on both sides of the man. The color and symbols in figure 2 above connote the group's fierce, eagerness, and readiness nature during the masquerade festival.

The interviewee for Noble's reported that the name "Noble" was chosen to represent the nobility of its members, and that also influences their decisions in admitting new members who wish to join the group. When admitting new members, leaders of the group lookout for unique and noble behaviour and attitude of the person before he/she is finally accepted as a member (I. Mensah, personal communication, March 24, 2019). 


\section{Egyaa No. 2}

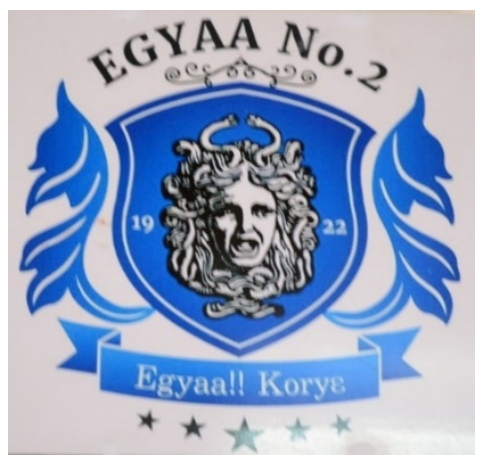

Figure 3. Emblem of Egyaa No. 2 (Source: Fieldwork, 2019)

Royal blue and the blackhead of Medusa are the elements that identify the group. Medusa was one of the three monstrous Gorgons, generally described as "winged human females" with living venomous snakes in place of hair. The primary colour of this group is Royal Blue. This colour was chosen and accepted because of the dominant occupation of the members being fisher-folks even though other members have different occupations in the area. The colour symbolizes the marine lifestyle of the Egyaa group.

\section{Tumus No. 3}

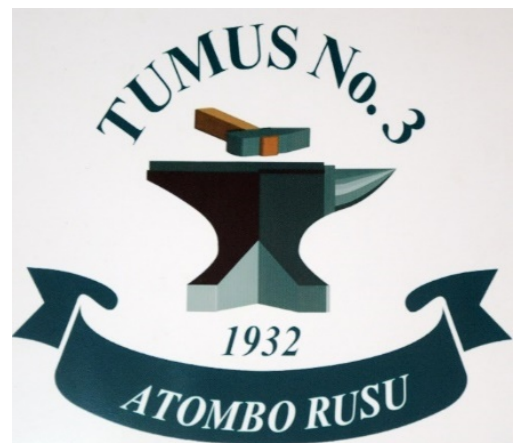

Figure 4. Emblem of Tumus No. 3 (Source: Fieldwork, 2019)

Green and white are the colour of the Tumus group. Green symbolizes life, growth, and medicinal purposes, while white indicates how victorious they are as a group. The emblem also represents the blacksmith's Anvil and a hammer. It signifies stability, solidity, and strength.

"...The colour green and white was chosen to represent the green and untouched nature of some vegetables and leaves (herbs) that human beings eat. These herbs were also used for herbal medicine and other stuff. When a seed is germinating, it starts with a green-coloured plant. The white represents victory..."

(Alhassan, personal communication, March 16, 2019).

The above assertion affirms Cerrato (2012) meaning of green, which symbolizes growth, harmony, freshness, and fertility.

All paraphernalia (Flags, Costumes, Masks, T-Shirts, Dues, Membership Cards, and others.) used by the group are designed with green and white colour and other colours.

\section{Red Cross No. 4}

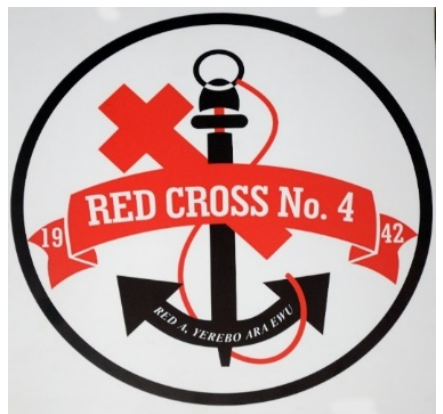

Figure 5. Emblem of Red Cross No. 4 (Source: Fieldwork, 2019)

Red is widely used to represent danger in some cultures. Red is also commonly associated with energy; 
hence, it is universally recognized as related to health and sporting activities because it is further seen as the symbol of life (Cerrato, 2012).

As the name implies, Red Cross have their colours as red, white, and black. The group's representative stated that their colours symbolize hospitality, the readiness of the group in terms of their activities, and how related they are to humanity. The emblem also has a black anchor that signifies stability and a black circle meant to keep all the elements within its confines together as one unit.

Royals No. 5

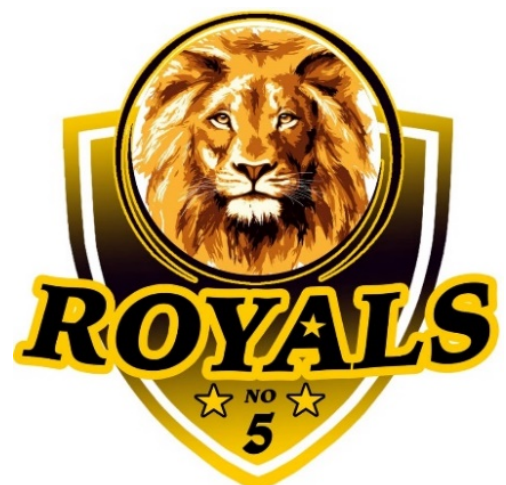

Figure 5. Emblem of Royals No. 5 (Source: Fieldwork, 2020)

The Royals' emblem is dominated by the head of a lion at the top of the emblem. The group's name "Royals" is written boldly in a serif font underneath the head of the lion and across a vector shape with a gradient of yellow, white, and black colours, which are the unique colours of the group, and two stars at the lower part of the emblem.

Cerrato (2012) postulates that yellow is perceived before other colours when put next to black; this combination is often used to issue a warning. Yellow produces a warming effect, arouses cheerfulness, stimulates mental activity, and generates muscle energy. It can be deduced that the energy associated with the colour yellow in the emblem also represents the muscle energy of the lion seen in the emblem. Pure or bright yellow is also often used to attract quick attention.

\section{Colour depicting Unity, Culture, and Actions based on colours used}

Individuals and groups of people use colour for diverse reasons. It may be due to its significance to them or an occasion and its symbolic meanings. The whole ceremony is a colour play, and the colours are used to tell a story. Interestingly, contingents from the same group wore costumes and masks with many different colours to display on the grounds. All the groups are only identified by the colours of their flags and symbols.

The significance of the various colours used connote unity. The aforementioned affirms Emiemokumo (2012) assertion that masquerade performances promote unity among various factions. This study observed that even though all the groups have their unique colours as evidenced from their emblems and apply several colours to the making of their costumes, they all perform as a unique uniform body. For example, members of a group that have used colours to make up their faces to look like Chiefs, FBI Agents, Ninja Turtles, Animals, Cheerleaders, cowboys, doctors, and the likes, come together to play their roles as a unified group.

The findings revealed that the idea of dressing like the aforementioned and others is to imitate the various professions of people from all over the world, e.g., Asians, Americans, Africans, and Europeans.

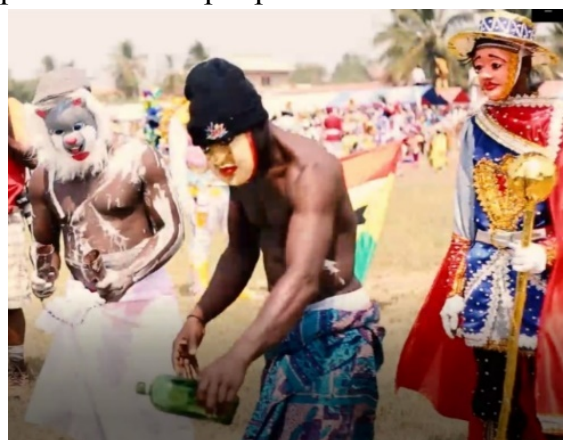

Figure 6. Actions: Fetish and Royal making libation (Source: Fieldwork, 2020)

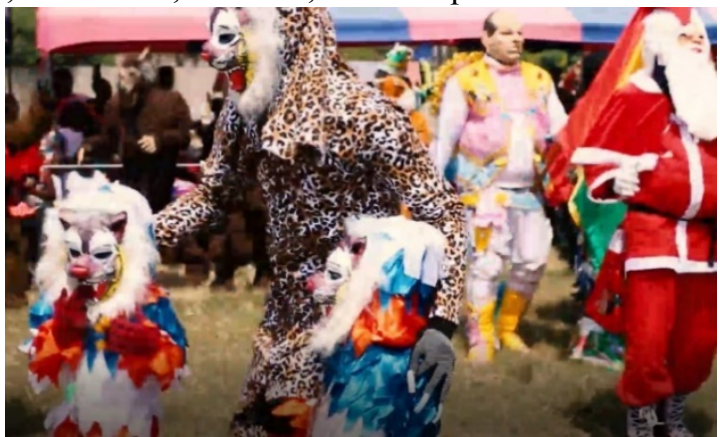

Figure 7. Animals, White Folk and Santa Claus (Source: Fieldwork, 2020)

Figure 6 above shows three people, two of them playing the role of Fetish Priests and making libations and incantations. The other person is dressed like a European Royal with his golden staff and apparel observing the incantations. The image above clearly depicts unity among people of the same kind but differentiated by their 
colours and costumes. The preceding sentence confirms the assertions of one of the interviewees. The interviewee asserts that "even though we have our cooperate colours for our groups, we also apply several colours to help achieve the kind of performance we want."

Figure 7 also depicts human beings dressed like animals of the same kind but different natures and another person in a Santa Claus costume performing on the same stage.

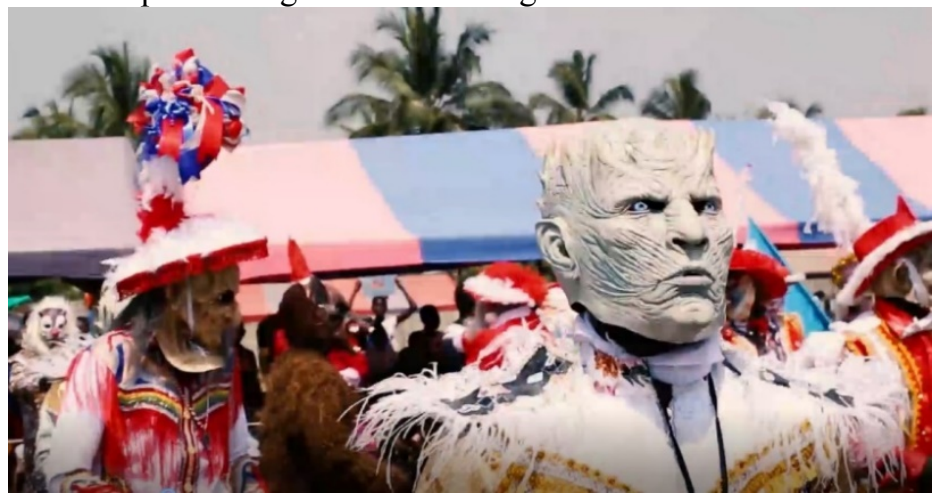

Figure 8. White Walk (Source: Fieldwork, 2020)

The figure above focuses on a masquerade dressed in a white costume with a mask portraying the White Walker King from the American HBO TV series, Game of Thrones. The use of white symbolizes coldness. The use of white in representing the character gives viewers a clear indication of the kind of environment the character (White Walker) lives in, a cold and snowy environment located somewhere in Europe, Asia, or America. The scene in the figure above was acted and staged in Winneba, to be specific Ghana, by one of the group participants during the Fancy Dress Festival. The figure above shows how cultures are boundless and appreciated and can be displayed and played by people from all walks of life through the use of colours. It also buttresses Agarkoh, Duku and Abban (2017) view that different cultures associate different colours with different meanings.

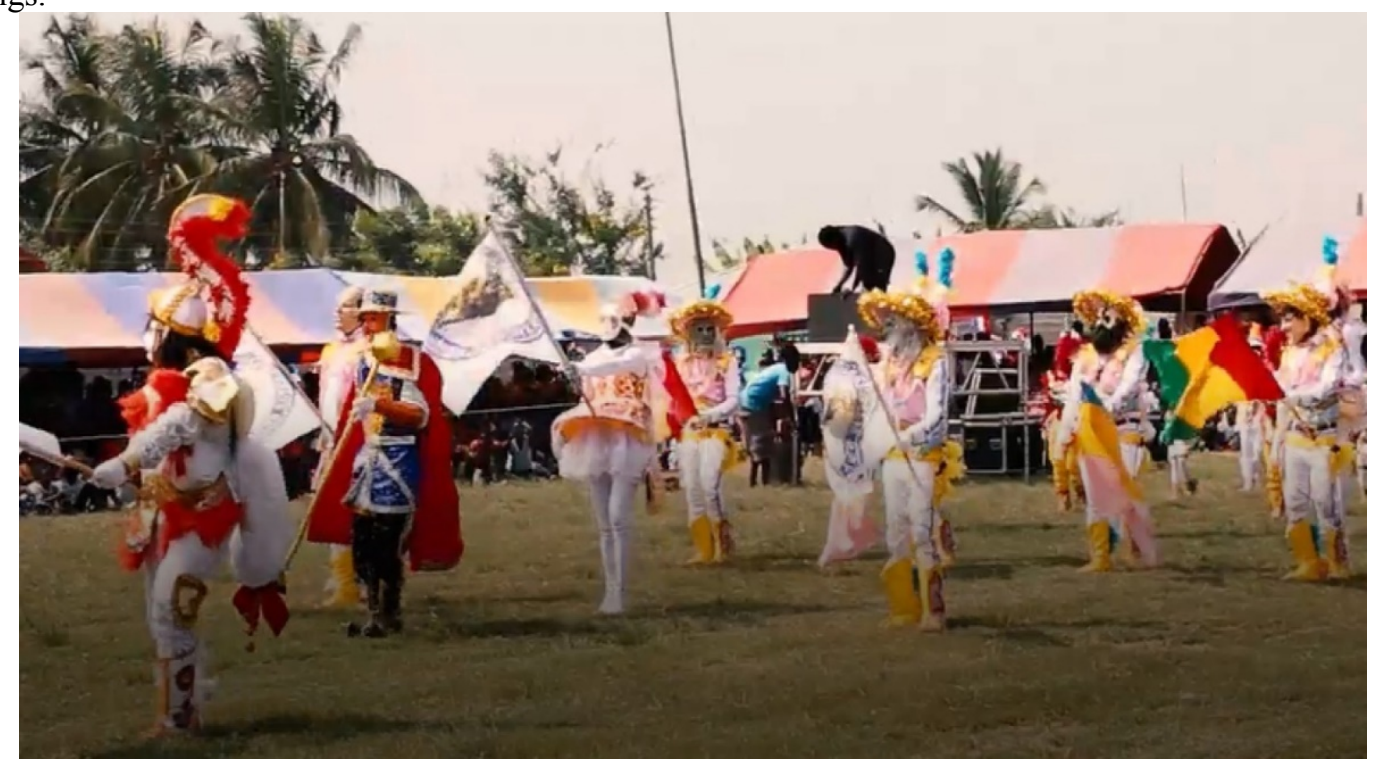

Figure 9. Procession of perceived Europeans (Source: Fieldwork, 2020)

Figure 9 shows a troupe of folks all dressed as white Europeans with a Royal leading the contingent, while each member in the troupe holds different flags but with emblems of the same kind representing a particular group. The use of several colours in figure 9 is intended to depict people from different origins coming together to form one group under the leadership of the influential authority. The figure symbolizes people sharing a standard feature, culture, and a more prominent organization leader. 


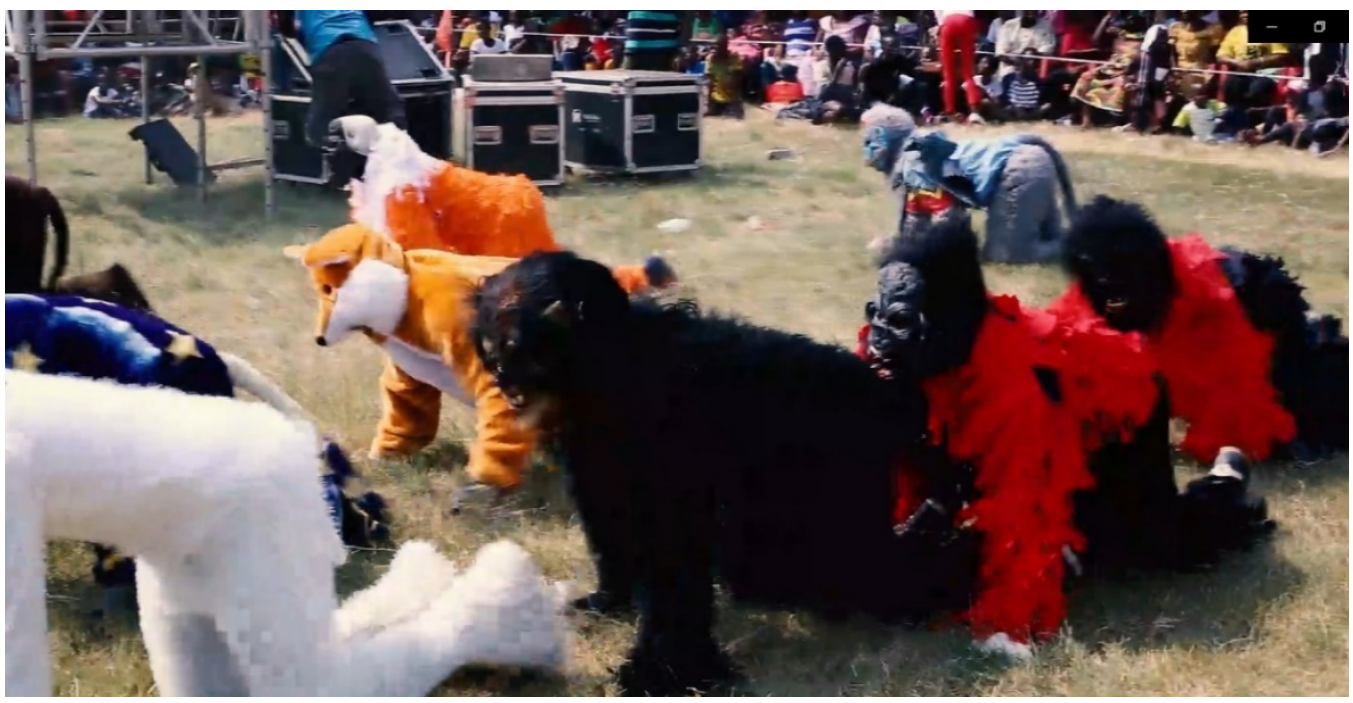

Figure 10. Creatures Kingdom (Source: Fieldwork, 2020)

The figure above (fig. 10) displays different animals, including a horrifying beast and a wolf trouping together. Wolves and other such beasts are creatures known to be dangerous, intense, ferocious, and voracious, with the ability to cause harm within and outside their territories. In this scene, these creatures are seen together, which gives the impression that they are of the same kind. The people playing the role of these creatures are representatives of any of the groups. They are, however, able to bring unity into their acts through colour and the makeup of their costumes. The use and significance of the colours (black, red, orange, white) by the masqueraders have simplified the identification of the troupe as a group of different wild creatures. Red, black, orange signify danger, strength, power, death, and aggression. Therefore, colours used in figure 6 indicate varieties of the same kind, character, and nature. Also, it was observed that their performance as those creatures shows that color can impact the performance of people (Elliot et al., 2007).

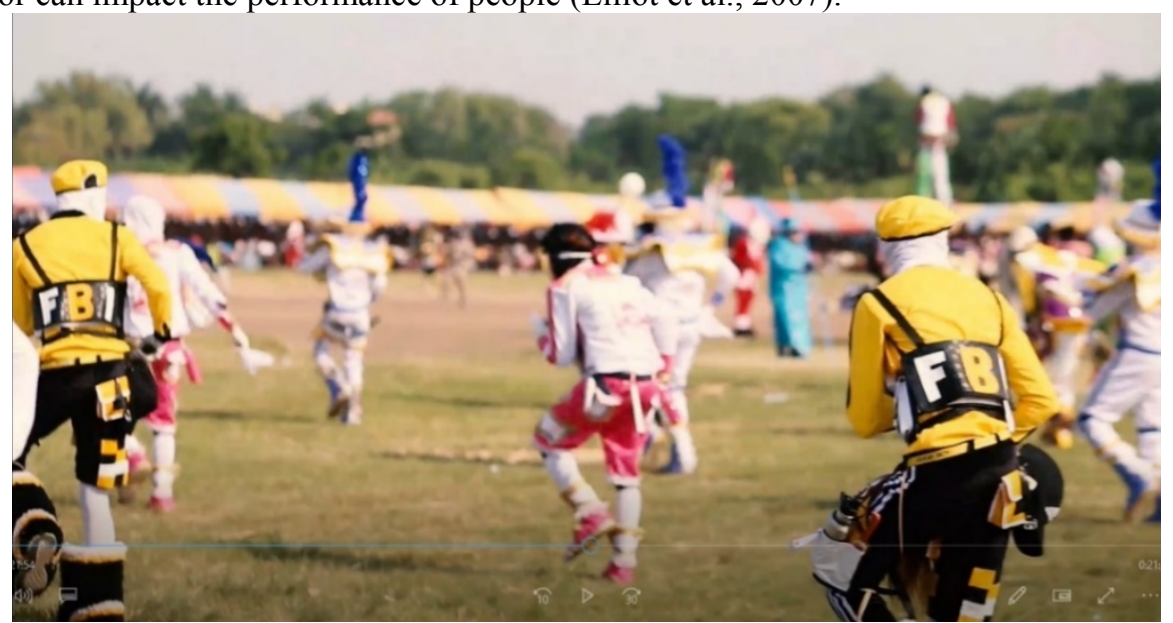

Figure 11. Group Performance (Source: Fieldwork, 2020)

Figure 11 identifies different people and professionals performing as a unified body. Two of them are FBI agents, others as European Royals and folks, and a Santa clause representative. The use of colours properly has helped in easy identification of the various professions in the troupes. 


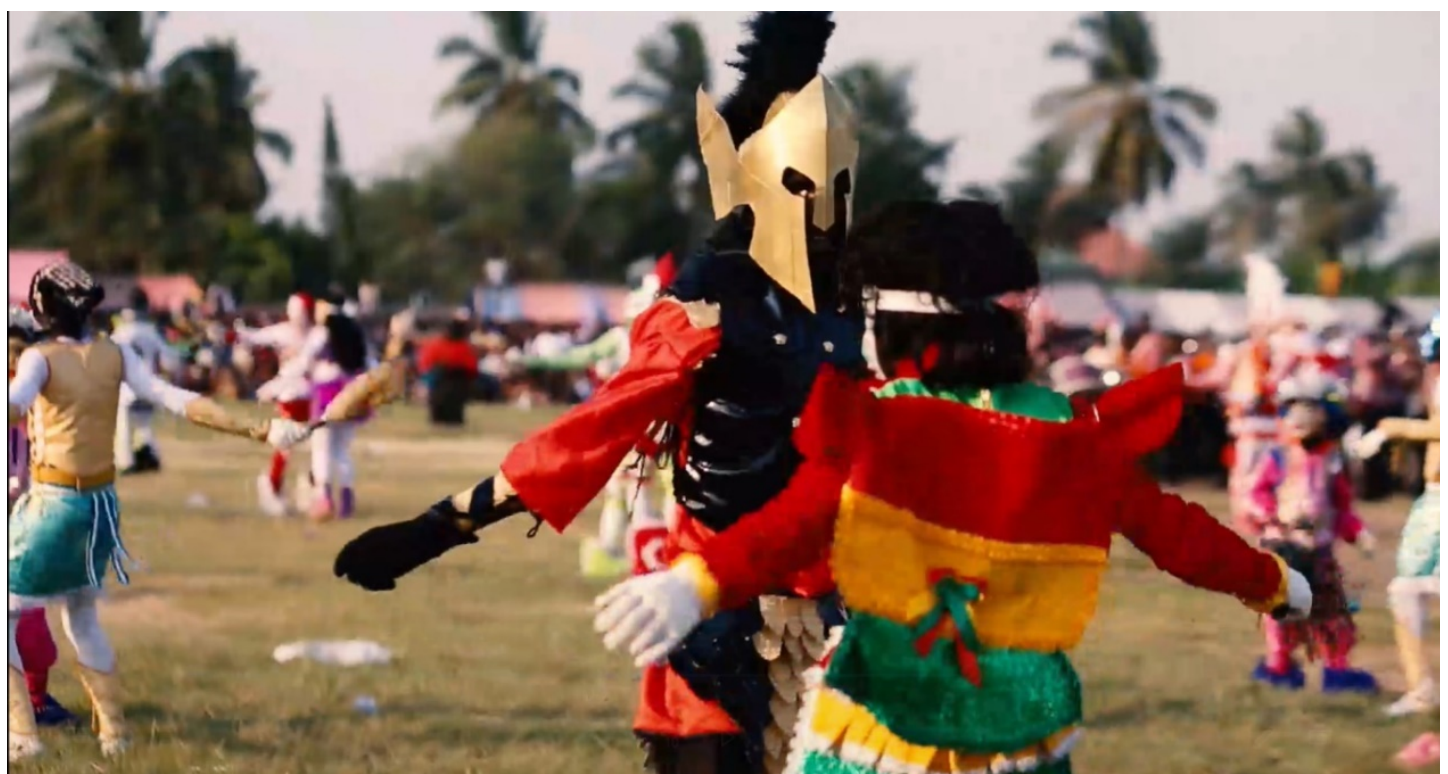

Figure 12. Chest Hugging (Source: Fieldwork, 2020)

The figure above (fig. 12) shows different kinds of people in different coloured costumes hugging each other. The closest in the image is like Fellbeast Rider (Nazgul from a foreign movie title "Lord of the Rings"), hugging a folk perceived to be African. The inculcation of the colours adds more beauty and organization to their performance. The fanciful nature of the act connotes excitement. The sophisticated and malevolent nature of the characters based on their costumes and performances also show togetherness.

Further findings also revealed that masqueraders choose the colours of costumes. Costumes of all the groups are sown differently by dressmakers of each group. Costumes designs are sown for four masqueraders as a unit in the same group. Observation and interviews further revealed that colours were mixed during the festivals regardless of the uniqueness of the groups. Masqueraders of Nobles No. 1 can also have Green and White Costumes sown in their style to perform for the Nobles even though the unique colours of Noble's are Green and White. The above description clearly shows how united all the groups are as people from the same town.

\section{Conclusion and Recommendations}

Colour is a very powerful essential that contributes to the festival's success. In applying colours for costumes and playing with colours, members of groups participating in the festival display some cultures known and associated with Europeans, Americans, Asians, and others. This way, the study reveals how the colours used for the costumes, to a very large extent, influence some members of some of the groups to mimic the nature and colour of others' costumes. Colour directly or indirectly influences people. The blend of different colours from the costumes of different groups generates unified actions and performances. In other words, the profuse use of colours in the Winneba Masquerade festival plays a significant role in the total enjoyment of the festival. The study further recommends that Graphic Designers or Art researchers experiment with the harmonious use of colours for costume makeup for the festival and whether it has cultural or traditional implications.

\section{References}

Agarkoh, E., Duku, F. K. \& Abban, E. (2017). Colour symbolism of Aboakyir. Journal of Culture, Society and Development, 36, 30-39.

Bernard, H. R. (2002). Research Methods in Anthropology: Qualitative and Quantitative Methods (3rd ed.). CA: Alta Mira Press.

Bertin, J. (1983). Semiology of graphics: diagrams, networks, maps. Berlin: de Gruyter Press

Braun, V., \& Clarke, V. (2006). Using thematic analysis in psychology. Qualitative Research in Psychology, Vol.3 (2)(ISSN1478-0887), 77-101.

Brown, K. E. (2005). Social Conflicts in Contemporary Effutu Festivals (M.S. thesis), Bowling Green State University, 35-69.

Cerrato, H. (2012). The meaning of colours: how colours impact our daily life, business, art, work and love. October 6, 2020. https://blocs.xtec.cat/.../files/2017/02/the-meaning-of-colours-book.pdf

Cox, L. K. (2021, August 17). Color Psychology in Marketing [Infographic]. https://blog.hubspot.com/marketing/psychology-of-color

De Bortoli, M. \& Maroto, J. (2001). Colours across cultures: Translating colours in interactive marketing 
communications. European Languages and the Implementation of Communication and Information Technologies, 1-27.

deGraft-Yankson, P. (2020). 'Of the Akan people: Colour and design education in Ghana', International Journal of Education Through Art, 16:3,pp. 399-416, doi: https://doi.org/10.1386/eta_00041_1

Elliot A. J., Maier M. A., Moller A. C., Friedman R. \& Meinhardt J. (2007). Color and psychological functioning: the effect of red on performance attainment. J Exp Psychol Gen. 2;136(1):154-68. doi:10.1037/00963445.136.1.154. Accessed 18 September 2021.

Emiemokumo, A. Augustine-Neto (2012). Visual art form in motion: traditional African masquerade as theatrical phenomenon. MGBAKOIGBA: Journal of African Studies, 1. 1-8.

Eru, K. G. (2013). What you ought to know about colours and communication. Retrieved July 27, 2019 from https://connectnigeria.com/articles/2013/06/what-you-ought-to-know-about-colours-andcommunication/\#targetText=Colour

Flick, U. (2013). Qualitative Data Analysis. The Sage Handbook of Qualitative Data Analysis.

Morse, N. \& Volley, J. (2018). We can use colour to communicate how we feel - here's how. Retrieved July 20 , 2020 from www.theconversation.com/we-can-use-colour-to-communicate-how-we-feel-heres-how-90157

Pierson, A. (2008). Colour: The influence on visual communication. Bemidji State University. Honours Program Thesis.

Schloss, K. B., Lessard, L., Walmsley, C. S. \& Foley, K. (2018). Colour inference in visual communication: the meaning of colours in recycling. Cognitive Research: Principles and Implications, 3:5

Schensul, Stephen L.; Schensul, Jean J. \& LeCompte, Margaret D. (1999). Essential ethnographic methods: observations, interviews, and questionnaires (Book 2 in Ethnographer's Toolkit). AltaMira Press.

"Tourism destination". www.modernghana.com. Retrieved March 2, 2020.

"Places of Interest - Winneba". www.ghanaexpeditions.com.

"Winneba travel guide". /www.world66.com. Retrieved June 15, 2020.

Ware, C. (2012). Information visualization: perception for design. Elsevier.

Yin, R. K. (2014). Case study research: Design and methods ( $5^{\text {th }}$ ed.). Thousand Oaks, CA: Sage Publications

Stephen Osei Akyiaw. Stephen became a Lecturer in the University of Education, Winneba in February 2018. Stephen was born in Dansoman, Accra on the $3^{\text {rd }}$ August, 1985. Stephen has a Master of Philosophy Degree in Communication and Media Studies (Business Communication Option) which he completed in 2017, and a Bachelor of Arts Degree in Graphic Design (completed in 2014), all from the University of Education, Winneba, Ghana. Stephen area of specialization is advertising, graphic design and entrepreneurship. 